\title{
Pengaruh Talent Management dan Knowledge Management Terhadap Kinerja Karyawan PT. Perkebunan Nusantara II (Survei Pada Kantor Direksi Tanjung Morawa)
}

\author{
Hilma Harmen \\ Staf Pengajar Jurusan Manajemen FE Unimed \\ Muhammad Tri Darma \\ Alumni Jurusan Manajemen FE Unimed
}

*Corresponding author: E-mail: hilmaharmen@gmail.com, Muhammadtridarma@gmail.com

\section{Abstrak}

Penelitian ini bertujuan untuk mengetahui pengaruh talent management dan knowledge management terhadap kinerja karyawan PT. Perkebunan Nusantara II Tanjung Morawa. Populasi dalam penelitian ini sebanyak 522 orang karyawan, dan sampel sebanyak 84 orang menggunakan teknik sampel stratifikasi. Teknik pengumpulan data yang digunakan adalah melalui angket (kuesioner) yang pengukurannya dengan skala likert dan diolah secara statistik menggunakan analisis regresi berganda dan pengujian hipotesis uji t, uji f, dan koefisien determinan.

Dari analisis data masing-masing variabel diperoleh persamaan regresi berganda $\mathbf{Y}=\mathbf{5 , 6 1 2}$ + 0,469 $X_{1}+0,598 X_{2}+$ e. Diperoleh $R^{2}$ sebesar 0,756, yang berarti $X_{1}$ dan $X_{2}$ menjelaskan pengaruh terhadap variabel $Y$ sebesar $75,6 \%$ sedangkan sisanya dijelaskan variabel lain diluar penelitian. Uji parsial yang dihasilkan masing-masing variabel bebas berpengaruh terhadap variabel terikat dengan signifikansi penelitian lebih kecil dari 0,1 sehingga hipotesis diterima, serta hasil perhitungan uji simultan sebesar 125,217 dengan ftabel 2,37 yang artinya $F_{\text {hitung }}>F_{\text {tabel }}$ dengan level of significant $(\alpha) 0,000<0,1$, yang artinya hipotesis diterima yaitu talent management dan knowledge management secara bersama-sama berpengaruh signifikan terhadap kinerja karyawan PT. Perkebunan Nusantara II Tanjung Morawa.

Kata Kunci: Talent Management, Knowledge Management, Kinerja Karyawan

\begin{abstract}
This study aims to determine the influence of talent management and knowledge management on the performance of employees of PT. Perkebunan Nusantara II Tanjung Morawa. The population in this study as many as 522 employees, and a sample of 84 people using stratification sample technique. Data collection technique used is through questionnaire (measurement) with the likert scale and processed statistically using multiple regression analysis and testing of $\mathrm{t}$ test hypothesis, $\mathrm{f}$ test, and determinant coefficient.

From the data analysis of each variable obtained by multiple regression equation $\mathrm{Y}=5,612+$ $0,469 \mathrm{X} 1+0,598 \mathrm{X}_{2}+$ e. Obtained R2 of 0.756 , which means $\mathrm{X}_{1}$ and $\mathrm{X}_{2}$ explain the effect on the variable $\mathrm{Y}$ of $75.6 \%$ while the rest described other variables outside the study. The partial test of each independent variable has an effect on the dependent variable with the research significance is smaller than 0.1 so the hypothesis is accepted, and the result of simultaneous test calculation is 125.217 with ftable 2.37 which means Fcount> Ftable with level of significant $(\alpha) 0.000<0.1$, which means that the accepted hypothesis of talent management and knowledge management together have a significant effect on the performance of employees of PT. Perkebunan Nusantara II Tanjung Morawa.
\end{abstract}

Keywords: Talent Management, Knowledge Management, Employee Performance. 


\section{PENDAHULUAN}

Sumber daya manusia merupakan faktor yang mutlak diperlukan dalam suatu organisasi, baik pada instansi pemerintah, perusahaan, atau pada usaha-usaha sosial dimana ia mendapatkan suatu balas jasa atau imbalan tertentu. Perkembangan dunia usaha akan terealisasi apabila ditunjang oleh sumber daya manusia yang berkualitas. Perkembangan ilmu pengetahuan dan teknologi informasi pada era globalisasi saat ini, mendorong organisasi untuk mampu menganalisis dan mengantispasi setiap perubahan lingkungan atau iklim bisnis dengan memberikan respon yang tanggap secara cepat, tepat, efektif, dan efisien, oleh karena itu setiap organisasi dituntut untuk memiliki Sumber Daya Manusia (SDM) yang handal dan berkualitas untuk melakukan kegiatan operasional organisasi.

SDM merupakan faktor strategis dalam semua kegiatan organisasi yang berfungsi sebagai penentu arah kebijakan dan kinerja organisasi dalam mencapai tujuan yang diharapkan. Tujuan organisasi tentunya dapat tercapai apabila kinerja karyawan dapat dimaksimalkan. Perencanaan SDM akan dapat dilakukan dengan baik dan benar jika perencanaannya mengetahui apa dan bagaimana SDM itu. SDM terdiri dari daya pikir dan daya fisik setiap manusia. Mahmudi (dalam Nisa, dkk., 2016) mengungkapkan bahwa terdapat beberapa faktor yang mempengaruhi kinerja SDM yaitu faktor individu, faktor kepemimpinan, faktor tim, faktor sistem, dan faktor situasi. Faktor pertama yang mempengaruhi kinerja karyawan adalah faktor individu yang didalamnya termasuk talenta dan pengetahuan sebagai kemampuan yang dimiliki individu sejak lahir.

Organisasi yang mempunyai karyawan dengan talent yang sesuai kebutuhan organisasi/perusahaan akan membuat perusahaan lebih kompetitif. Dengan semakin besarnya kesadaran perusahaan-perusahaan akan talent tersebut, maka dewasa ini mereka bersaing untuk mendapatkan karyawan yang bertalenta tinggi, baik dengan cara mencari dari luar maupun dari pelatihan dan kaderisasi. Kekurangan talent merupakan hal serius bagi pertumbuhan organisasi di masa depan. Dengan demikian merekrut dan mempertahankan orang-orang yang memiliki talent menjadi penting. Hal ini dikenal sebagai talent management atau manajemen bakat (Endratno dalam Syahputra, dkk. 2016).

Menurut Pella \& Inayati (dalam Syahputra, dkk., 2016) salah satu manfaat dari pelaksanaan program manajemen talenta adalah tersedianya terus menerus karyawan yang mencapai potensi terbaik mereka masing-masing dan meningkatkan kinerja yang ada dalam intitusi atau perusahaan.

Talent management adalah serangkaian proses yang dilakukan perusahaan untuk mengidentifikasi, mengembangkan, mempertahankan, dan menempatkan orang yang tepat di tempat yang tepat. Capelli (dalam Syahputra, dkk., 2016) berpendapat bahwa: "Talent management berkaitan dengan mencari orang yang tepat dengan keterampilan yang tepat untuk posisi yang tepat." semakin besarnya kesadaran perusahaan-perusahaan akan talent tersebut, maka dewasa ini mereka bersaing untuk mendapatkan karyawan yang bertalenta tinggi, baik dengan cara mencari dari luar maupun dari pelatihan dan kaderisasi.

Selain talent, pendidikan dan ilmu pengetahuan turut berperan penting dalam mempersiapkan SDM yang berkualitas dan kompetitif. Ketatnya kompetisi secara global mendorong perusahaan untuk terus meningkatkan kinerja perusahaannya, oleh karena itu SDM yang berkualitas dengan penguasaan pengetahuannya menjadi pilihan penting yang harus dilakukan untuk mencapai visi perusahaan. Pengetahuan telah menjadi sesuatu yang sangat menentukan, oleh karena itu perolehan dan pemanfaatannya perlu dikelola dengan baik 
dalam konteks peningkatan kinerja karyawan.

Seiring dengan semakin berkembangnya ilmu pengetahuan dan teknologi dari masa kemasa, inovasi yang mampu dihasilkan oleh manusia pun semakin berkembang. Fenomena ini merupakan konsekuensi logis dari adanya dinamika masalah dan kebutuhan hidup manusia yang selalu hadir dan semakin meningkat. Untuk menjaga agar proses inovasi dan pembaharuan terus berkembang dan berkesinambungan, dibutuhkan sarana atau kegiatan yang mampu memfasilitasi setiap individu atau anggota organisasi untuk menyampaikan gagasan atau idenya. Hasil riset Delphi Group menunjukkan bahwa pengetahuan atau knowledge dalam organisasi, $42 \%$ tersimpan dan terstruktur di pikiran atau otak karyawan, $26 \%$ pada dokumen kertas, $20 \%$ pada dokumen elektronik, dan $12 \%$ berupa knowledge base elektronik (Satiarso dalam Saefullah \& Rusdiana, 2016:165).

Menurut Kosasih (2007) kinerja karyawan akan mencapai hasil yang lebih maksimal apabila didukung dengan knowledge yang dimiliki. Setiap karyawan diharapkan dapat terus menggali pengetahuannya dan tidak hanya bergantung atau terpaku pada sistem yang ada. Sehingga dapat dikatakan bahwa setiap karyawan mempunyai peran di dalam meningkatkan perusahaannya. Seperti yang dikatakan oleh Fatwan (dalam Kosasih, 2007) faktor yang mempengaruhi lingkungan bisnis saat ini bukan lagi era informasi, tetapi sudah beralih ke era pengetahuan.

Knowledge management adalah serangkaian proses penciptaan, pengkomunikasian dan penerapan knowledge perusahaan sebagai pembelajaran untuk meningkatkan kinerja karyawan maupun organisasi. Proses pengembangan talenta karyawan tidak lepas kaitannya dengan pengelolaan pengetahuan yang tepat. Sistem talent management yang dilaksanakan secara terpadu dan selaras dengan knowledge management dapat meningkatkan kinerja karyawan.

Salah satu hal terpenting dalam pencapaian tujuan perusahaan adalah kinerja sumber daya manusia yang ada didalamnya. Setiap perusahaan pasti mengharapkan kinerja yang maksimal dari seluruh karyawannya karena hal tersebut akan berdampak pada pencapaian target dan tujuan perusahaan. Oleh hal itu, dibutuhkan SDM-SDM yang memiliki kinerja yang tinggi.

Permasalahan mengenai kinerja merupakan permasalahan yang akan selalu dihadapi oleh pihak manajemen perusahaan, karena itu manajemen perlu mengetahui faktor-faktor yang mempengaruhi kinerja karyawan. Faktor-faktor yang dapat mempengaruhi kinerja karyawan tersebut akan membuat manajemen perusahaan dapat mengambil berbagai kebijakan yang diperlukan, sehingga dapat meningkatkan kinerja karyawannya agar sesuai dengan harapan perusahaan.

PT. Perkebunan Nusantara II (Persero) Tanjung Morawa yang bergerak dalam bidang agribisnis perkebunan adalah salah satu Badan Usaha Milik Negara (BUMN) yang mengelola budidaya kelapa sawit, karet, tembakau dan tebu. PT. Perkebunan Nusantara II dibentuk berdasarkan Peraturan Pemerintah (PP) Nomor 7 tahun 1996 tanggal 14 Februari 1996 tentang peleburan Perusahaan Perseroan (Persero) PT. Perkebunan II dan Perusahaan Perseroan (Persero) PT Perkebunan IX menjadi PerusahaanPerseroan (Persero) PT. Perkebunan Nusantara II. PT. Alasan dari pemilihan lokasi penelitian, dikarenakan PT. Perkebunan Nusantara II (Persero) Tanjung Morawa merupakan salah satu perusahaan yang mengimplementasikan talent management dan knowledge management untuk mengelola SDM agar mencapai kinerja yang maksimal.

\section{METODE PENELITIAN}




\section{Lokasi Penelitian}

Penelitian ini dilakukan pada kantor direksi PT. Perkebunan Nusantara II Tanjung Morawa di Jalan Raya Medan - Tanjung Morawa, Km. 16, Tanjung Morawa 20362, Kabupaten Deli Serdang. Telp. (061) 7940055.

\section{Populasi dan Sampel}

Dalam penelitian ini populasi yang digunakan adalah seluruh karyawan yang ada pada kantor kandir PT. Perkebunan Nusantara II (Survei Pada Kantor Direksi Tanjung Morawa) yang berjumlah 522 karyawan. Menurut Arikunto (2006 : 27) sampel adalah sebagai wilayah dan populasi yang diteliti, dimana apabila objeknya kurang dari 100 orang lebih baik diambil seluruhnya sehingga penelitiannya merupakan penelitian populasi. Sebaliknya jika jumlah subjeknya besar dapat diambil antara $10-15 \%$ atau 20-55\%. Untuk menentukan jumlah sampel dalam penelitian ini digunakan rumus Slovin, sebagai berikut:

$$
n=\frac{N}{1+N e^{2}}
$$

Dimana:

$$
\mathrm{n}=\text { Jumlah Sampel }
$$

$\mathrm{N}=$ Jumlah Populasi

$\mathrm{e}=$ Batas toleransi kesalahan (error tolerance)

Dari jumlah populasi tersebut dengan batas toleransi kesalahan 10\%, maka dengan menggunakan rumus diatas diperoleh sampel sebesar:

$$
n=\frac{522}{1+522(0,1)^{2}}=83,9=84 \text { orang }
$$

Berdasarkan rumus Slovin, maka jumlah sampel dalam penelitian ini dapat diketahui sebanyak 84 orang. Teknik pengambilan sampel yang dipakai dalam penelitian ini adalah sampel stratifikasi (Stratified Sampling) yaitu peneliti membagi populasi menjadi beberapa kelompok dan secara random memilih subsampel dari setiap kelompok (Kuncoro, 2013:127).

Tabel 1

Jumlah Populasi dan Sampel

\begin{tabular}{|c|c|c|c|}
\hline No & Divisi & Populasi & Sampel \\
\hline 1 & D. Komisaris & 3 & - \\
\hline 2 & Sekr. Dekom/Organ Pendukung & 8 & 1 \\
\hline 3 & Direksi & 3 & - \\
\hline 4 & Sekretariat & 154 & 25 \\
\hline 5 & Satuan Pengawasan Intern & 18 & 3 \\
\hline 6 & Tanaman & 30 & 6 \\
\hline 7 & Teknik/Pengolahan \& Lingkungan & 28 & 5 \\
\hline 8 & Pembiayaan & 58 & 9 \\
\hline 9 & Sumber Daya Manusi & 31 & 5 \\
\hline 10 & Komersil & 31 & 5 \\
\hline 11 & Hukum dan Pertanahan & 17 & 3 \\
\hline 12 & Umum & 95 & 15 \\
\hline 13 & Perencanaan dan Pengembangan & 23 & 4 \\
\hline 14 & Adhock Panitia Pelelangan Barang dan & 7 & 1 \\
\hline
\end{tabular}




\begin{tabular}{|c|c|c|c|}
\hline 15 & MBT & 13 & 2 \\
\hline 16 & DPB & 3 & - \\
\hline \multicolumn{2}{|c|}{ Jumlah } & $\mathbf{5 2 2}$ & $\mathbf{8 4}$ \\
\hline
\end{tabular}

\section{Variabel Penelitian dan Definisi Operasional}

\section{Variabel Penelitian}

Adapun yang menjadi variabel dalam penelitian ini adalah sebagai berikut:

1. Variabel bebas (Independen):
a. $\left(\mathrm{X}_{1}\right)$
: Talent Management
b. $\left(X_{2}\right)$
Knowledge
Management

2. Variabel terikat(Dependen):
a. (Y)
: Kinerja Karyawan

\section{Definisi Operasional}

a. Talent Management $\left(\mathrm{X}_{1}\right)$

Adalah proses mengidentifikasi, merekrut, mengembangkan, dan mempertahankan karyawan yang bertalenta untuk ditempatkan ditempat yang sesuai kebutuhan perusahaan dan sesuai strategi perusahaan.

Indikator talent management dalam penelitian ini adalah:

1. Perekrutan dan seleksi

2. Perencanaan sukses

3. Pelatihan dan pengembangan

4. Proses manajemen kinerja

5. Kompensasi

6. Retensi

b. Knowledge Management $\left(\mathrm{X}_{2}\right)$

Adalah proses memperoleh dan mendayagunakan data, informasi, wawasan, instuisi, dan pengalaman untuk kemajuan organisasi.

Indikator knowledge management dalam penelitian ini adalah:

1. Teknologi
2. Prosedur pekerjaan

3. Pengetahuan pribadi

c. Kinerja Karyawan (Y)

Adalah hasil yang dicapai karyawan dalam pelaksanaan suatu pekerjaan yang telah menjadi tanggungjawabnya dan hasil yang diberikan sesuai dengan standar operasional perusahaan.

Indikator kinerja karyawan dalam penelitian ini adalah:

1. Kualitas

2. Kuantitas

3. Ketepatan waktu

4. Efektifitas biaya

5. Butuh pengawasan

6. Dampak interpersonal

\section{Teknik Pengumpulan Data}

Teknik pengumpulan data menggunakan dilakukan melalui:

a. Studi dokumen

Studi dokumen dilakukan dengan cara mengumpulkan data dan informasi dari buku, jurnal, dan internet yang berkaitan dengan penelitian.

b. Wawancara

Wawancara yaitu pengajuan beberapa pertanyaan oleh peneliti untuk tujuan memperoleh informasi yang relevan.

c. Angket/Kuesioner

Angket merupakan salah satu alat pengumpulan data dengan membuat sejumlah pertanyaan tertulis yang 
digunakan untuk memperoleh informasi dari responden.
Skala penilaian yang digunakan untuk setiap responden adalah skala likert dengan ketentuan sebagai berikut

Tabel 2

Pedoman Pemberian Skor

\begin{tabular}{|c|c|c|}
\hline No. & Pernyataan & Skor \\
\hline 1 & SS = Sangat Setuju & 5 \\
\hline 2 & S = Setuju & 4 \\
\hline 3 & RR = Ragu-ragu & 3 \\
\hline 4 & TS = Tidak Setuju & 2 \\
\hline 5 & STS = Sangat Tidak Setuju & 1 \\
\hline
\end{tabular}

Uji heterokedastisitas bertujuan

\section{Teknik Analisis Data}

\section{Uji Asumsi Klasik}

\section{Uji Normalitas}

Uji normalitas bertujuan untuk menguji apakah dalam model regresi variabel pengganggu atau residual memiliki distribusi normal. Seperti diketahui bahwa uji $\mathrm{t}$ dan $\mathrm{F}$ mengasumsikan bahwa nilai residual mengikuti distribusi normal. Ada dua cara untuk mendeteksi apakah residual berdistribusi normal atau tidak yaitu dengan analisis grafik dan uji statistik.

\section{Uji Multikolinearitas}

Uji multikolinearitas bertujuan untuk menguji apakah pada model regresi ditemukan adanya korelasi antar variabel bebas. Model regresi yang baik seharusnya bebas dari multikoliniearitas atau tidak terjadi korelasi diantara variabel bebas.

\section{Uji Heterokedastisitas}

untuk menguji apakah dalam model regresi terjadi ketidaksamaan varians dari residual satu pengamatan ke pengamatan yang lain. Jika varians dari residual satu pengamatan lain tetap, maka disebut homokedastisitas dan jika berbeda disebut heterokedastisitas. Model regresi yang baik adalah homokedastisitas, yakni varians dan residual satu pengamatan lain tetap.

\section{Analisis Regresi Linear Berganda}

Analisis regresi digunakan untuk mengetahui seberapa besar pengaruh variabel $\mathrm{X}_{1}$ (Talent Management) dan $\mathrm{X}_{2}$ (Knowledge Management) terhadap variabel Y (Kinerja Karyawan).

Dalam penelitian ini analisis regresi yang digunakan adalah analisis regresi liniear berganda dengan bentuk persamaan:

$$
\mathrm{Y}=\mathrm{a}+\mathrm{b}_{1} \mathrm{x}_{1}+\mathrm{b}_{2} \mathrm{X}_{2}+\mathrm{e}
$$

Dimana:

$$
\begin{array}{ll}
\mathrm{Y} & =\text { Kinerja Karyawan } \\
\mathrm{a} & =\text { Konstanta } \\
\mathrm{X}_{1} & =\text { Talent Management } \\
\mathrm{X}_{2} & =\text { Knowledge Management }
\end{array}
$$


$\mathrm{b}_{1} \quad=$ Koefisien Talent Management

$\mathrm{b}_{2} \quad=$ Koefisien Knowledge Management

e $\quad=$ Standar eror

\section{Pengujian Hipotesis}

\section{Uji t}

Uji t digunakan untuk menguji secara parsial apakah variabel bebas $\left(\mathrm{X}_{1}, \mathrm{X}_{2}\right)$ mempunyai pengaruh signifikan terhadap nilai variabel terikat (Y) dengan rumusan hipotesa sebagai berikut:

a. Ho: $b_{1}=b_{2}=0$, artinya variabel bebas $\left(\mathrm{X}_{1}, \mathrm{X}_{2}\right)$ tidak mempunyai pengaruh signifikan terhadap variabel terikat (Y).

b. Ha: $b_{1} \neq b_{2} \neq 0$, artinya variabel bebas $\left(\mathrm{X}_{1}, \mathrm{X}_{2}\right)$ memiliki pengaruh yang signifikan terhadap variabel terikat (Y).

c. Kriteria pengambilan keputusan:

Ho diterima jika $t_{\text {hitung }}<t_{\text {tabel }}$, pada $\alpha=$ $10 \%$

Ha diterima jika $t_{\text {hitung }}>t_{\text {tabel }}$, pada $\alpha=$ $10 \%$

Adapun rumus yang digunakan untuk menguji masing-masing hipotesis ini adalah dengan rumus uji $t$ parsial (Ridwan, 2007:125) yaitu:

$t_{\text {hitung }}=\frac{\sqrt[7]{n-2}}{\sqrt{n-r^{2}}}$

Dimana:

$r=$ Koefisien korelasi

$\mathrm{n}=$ Jumlah ke-n
Uji F

Uji $\mathrm{F}$, untuk menguji hipotesis yang diajukan rumusan hipotesis sebagai berikut:

a. Ho: $\mathrm{b}_{1}=\mathrm{b}_{2}=0$, artinya variabel bebas $\left(\mathrm{X}_{1}, \mathrm{X}_{2}\right)$ secara serentak tidak ada pengaruh signifikan terhadap variabel terikat $(Y)$.

b. Ha: $b_{1} \neq b_{2} \neq 0$, artinya variabel bebas $\left(\mathrm{X}_{1}, \mathrm{X}_{2}\right)$ secara serentak terdapat pengaruh yang signifikan terhadap variabel terikat $(\mathrm{Y})$.

c. Kriteria pengambilan keputusan:

Ho diterima jika $\mathrm{F}_{\text {hitung }}<\mathrm{F}_{\text {tabel }}$, pada $\alpha$ $=10 \%$

Ha diterima jika $\mathrm{F}_{\text {hitung }}>\mathrm{F}_{\text {tabel }} \mathrm{l}$, pada $\alpha$ $=10 \%$

Adapun rumus yang digunakan untuk mengetahui tingkat signifikansi variabel $\mathrm{X}_{1}$ dan $\mathrm{X}_{2}$ secara bersama-sama terhadap variabel $\mathrm{Y}$, digunakan rumus uji $\mathrm{F}$ regresi (Sugiyono, 2005), yaitu:

$F h=\frac{R^{2} / k}{\left(1-R^{2}\right) /(n-k-1)}$

Dimana:

$\mathrm{R}=$ koefisien korelasi ganda

$\mathrm{k}=$ jumlah variabel independen

$\mathrm{n}=$ jumlah anggota sampel

\section{Koefisien Determinasi $\left(\mathrm{R}^{2}\right)$}

Dari perhitungan $r$ (korelasi) dapat dilihat hubungan variabel bebas $\left(\mathrm{X}_{1}\right.$ dan $\left.\mathrm{X}_{2}\right)$ dan variabel terikat $(Y)$ positif atau negatif hubungan tersebut. Determinan digunakan untuk melihat kontribusi variabel bebas $\left(\mathrm{X}_{1}\right.$, $\mathrm{X}_{2}$ ) terhadap variabel terikat $(\mathrm{Y})$. 


\section{HASIL PENELITIAN}

\section{Uji Asumsi Klasik}

\section{Uji Normalitas}

Uji normalitas data bertujuan untuk mengetahui apakah data yang digunakan dalam model regresi telah terdistribusi secara normal atau tidak. Data yang berdistribusi normal artinya data sampel tersebut dapat mewakili populasi. Alat uji yang digunakan dalam penelitian ini adalah uji Normal Probability Plots, dimana bila titik-titik menyebar di sekitar garis diagonal serta penyebarannya mengikuti arah garis diagonal, maka data tersebut terdistribusi normal.

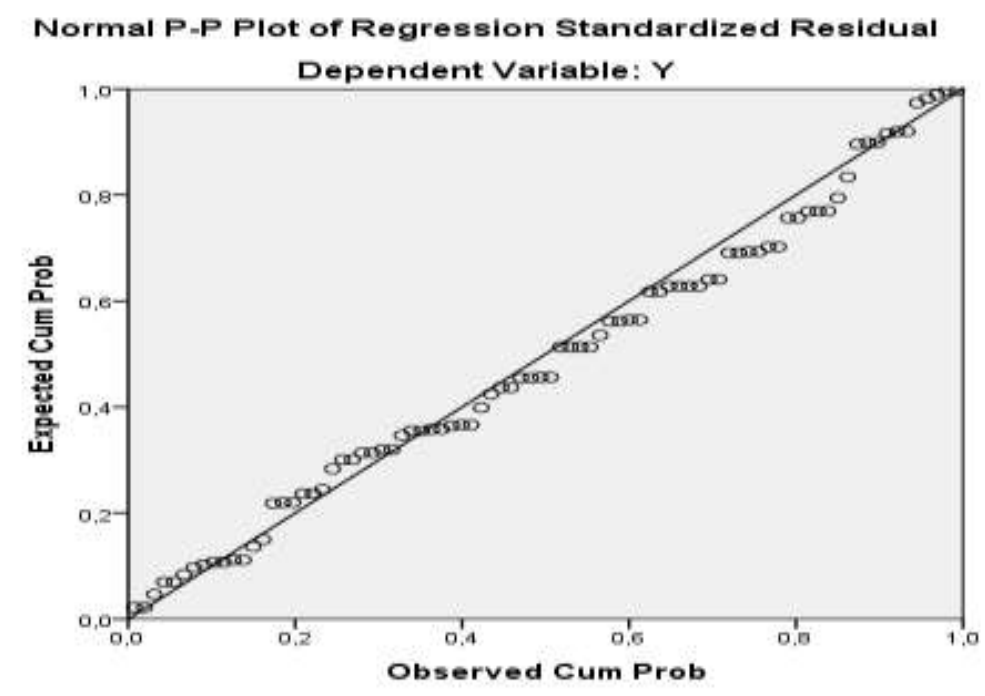

Gambar 1.

Normal P-P Plot of Regresion Standarized Residual

Pada gambar 1 terlihat bahwa titiktitik menyebar disekitar garis diagonal dan mengikuti arah garis diagonal. Berdasarkan hasil diatas, maka data dalam penelitian ini berdistribusi secara normal dan memenuhi uji normalitas data.

\section{Uji Multikolinearitas}

Uji multikolinieritas dilakukan untuk melihat apakah ada keterkaitan antara hubungan variabel-variabel bebas. Untuk mengetahui apakah ada atau tidaknya multikolinieritas di dalam model regresi, maka perlu dilakukan uji multikolinieritas yaitu dengan cara melihat VIF (Variance
Inflation Factor) dan toleransi. Dimana nilai VIF lebih kecil dari 10 dan nilai toleransi lebih besar dari 0,1.

Tabel 3

\section{Coefficients}

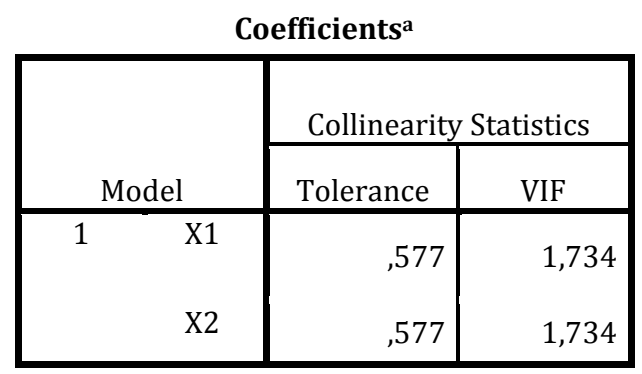


a. Dependent Variable: Y

Berdasarkan tabel 3 di atas dapat dilihat nilai toleransi untuk Talent Management $\left(\mathrm{X}_{1}\right)=0,577$ dan Knowledge Management $\left(\mathrm{X}_{2}\right)=0,577$, sedangkan VIF untuk Talent Management $\left(\mathrm{X}_{1}\right)=1,734$ dan Knowledge Management $\left(\mathrm{X}_{2}\right)=1,734$. Hal ini menunjukkan bahwa VIF lebih kecil dari 10 dan nilai toleransi lebih besar dari 0,10, maka dapat disimpulkan bahwa antar variabel bebas tidak terjadi multikolinieritas.

\section{Uji Heterokedastisitas}

Suatu model regresi linear berganda dapat dikatakan bebas dari permasalahan heterokedastisitas jika:

- Titik-titik data menyebar diatas dan dibawah atau sekitaran angka 0

- Titik-titik data tidak mengumpul hanya di atas atau dibawah saja.

- Penyebaran titik-titik data tidak boleh membentuk pola bergelombang, melebar kemudian menyempit dan melebar kembali.

- Penyebaran titik-titik data sebaiknya tidak berpola.

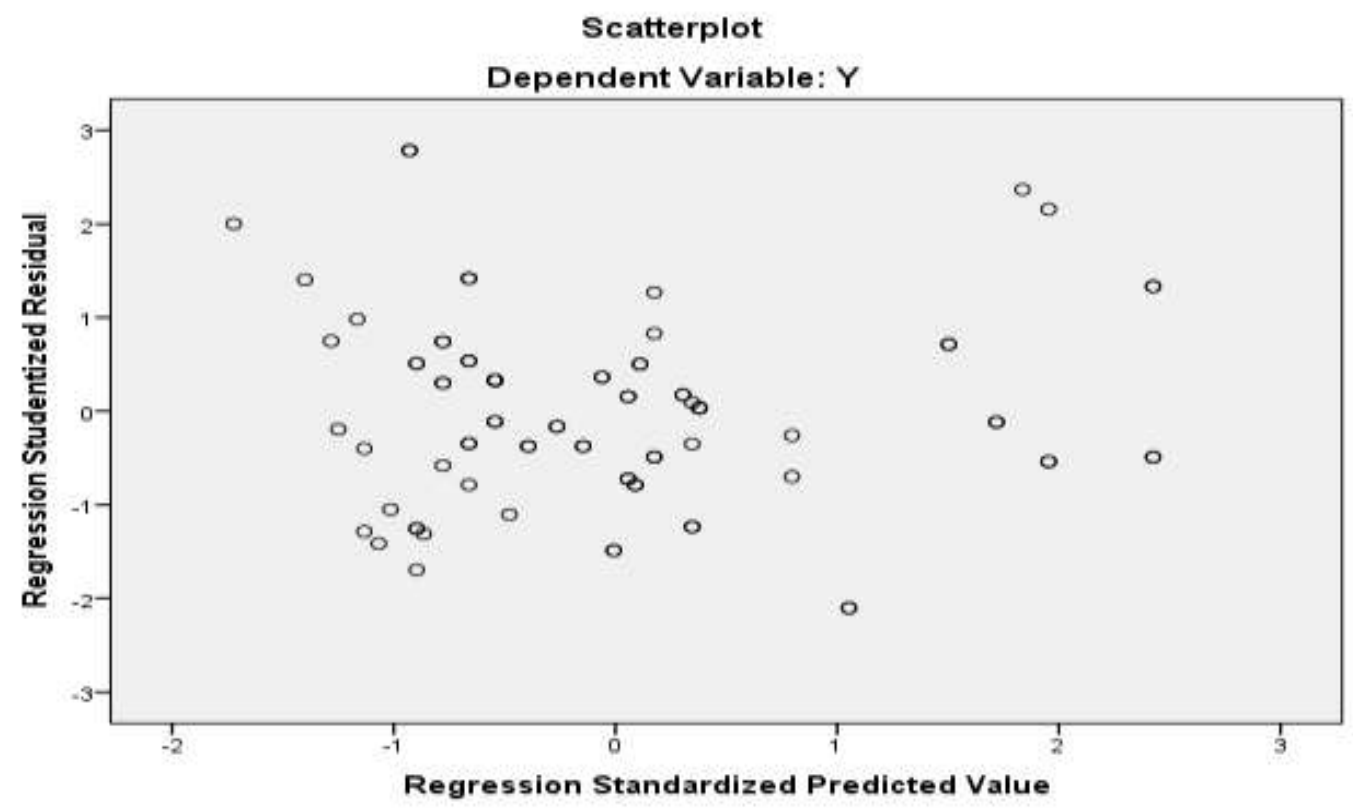

Gambar 2.

Scatterplot Regresi Standar Residual

Pada gambar 2 di atas menunjukkan bahwa titik-titik data menyebar disekitar angka nol dan tidak mengumpul di suatu titik. Penyebaran titik-titik data tersebut juga tidak membentuk suatu pola. Jadi dapat disimpulkan bahwa model regresi penelitian ini tidak mengalami permasalahan heterokedastisitas.

\section{Analisis Regresi Berganda}

Model regresi berganda dengan 1 variabel dependen (Y) yaitu Kinerja Karyawan dan 2 variabel independen $(\mathrm{X})$ yaitu variabel Talent Management $\left(\mathrm{X}_{1}\right)$ dan Knowledge Management $\left(\mathrm{X}_{2}\right)$ adalah sebagai berikut:

$$
Y=a+b_{1} X_{1}+b_{2} X_{2}+e
$$


Untuk menguji hipotesis yang digunakan analisis regresi berganda. menyatakan terdapat pengaruh Talent Berdasarkan hasil perhitungan diperoleh hasil Management $\left(\mathrm{X}_{1}\right)$ dan Knowledge Management persamaan regresi berganda sebagai berikut: $\left(\mathrm{X}_{2}\right)$ terhadap Kinerja Karyawan (Y)

\section{Tabel 4}

Hasil Uji Regresi Liniear Berganda

\begin{tabular}{|c|c|c|c|c|c|c|}
\hline \multirow{2}{*}{\multicolumn{2}{|c|}{ Model }} & \multicolumn{2}{|c|}{ Unstandardized Coefficients } & $\begin{array}{c}\text { Standardized } \\
\text { Coefficients }\end{array}$ & \multirow[b]{2}{*}{$\mathrm{t}$} & \multirow[b]{2}{*}{ Sig. } \\
\hline & & $\mathrm{B}$ & Std. Error & Beta & & \\
\hline 1 & (Constant) & 5,612 & 3,303 & & 1,699 & 093 \\
\hline & $\mathrm{X} 1$ & ,469 & 059 & ,575 & 7,952 & 000 \\
\hline & $\mathrm{X} 2$ & ,598 & 115 & 377 & 5,215 &, 000 \\
\hline
\end{tabular}

Dari hasil SPSS diatas dapat dijelaskan sebagai berikut:

$$
Y=5,612+0,469 X_{1}+0,598 X_{2}+e
$$

- Konstan sebesar 5,612 menyatakan bahwa jika tidak ada variabel X, maka kinerja karyawan adalah sebesar 5,612 dengan asumsi faktor lain konstan.

- Koefisien regresi variabel $\mathrm{X}_{1}$ sebesar 0,469 menyatakan bahwa setiap terjadi perubahan Talent Management $\quad 1 \%$ akan mempengaruhi kinerja karyawan sebesar 0,469 dengan asumsi faktor lain konstan.
- Koefisien regresi variabel $\mathrm{X}_{2}$ sebesar 0,598 menyatakan bahwa setiap terjadi peningkatan Knowledge Management $\quad 1 \% \quad$ akan mempengaruhi kinerja karyawan sebesar 0,598 dengan asumsi faktor lain konstan.

\section{Uji Hipotesis}

\section{Uji F (Simultan)}

Uji hipotesis secara simultan untuk mengetahui apakah model regresi sudah benar atautidak. Uji hipotesis ini menggungakan taraf signifikan, dan uji ini diperoleh dari tabel ANOVA berikut ini:

Tabel 5

Hasil Uji F (Simultan)

ANOVA $^{\mathrm{a}}$

\begin{tabular}{|c|c|c|c|c|c|c|}
\hline \multicolumn{2}{|c|}{ Model } & Sum of Squares & $\mathrm{df}$ & Mean Square & $\mathrm{F}$ & Sig. \\
\hline \multirow[t]{3}{*}{1} & Regression & 1316,583 & 2 & 658,292 & 125,217 &, $000^{\mathrm{b}}$ \\
\hline & Residual & 425,833 & 81 & 5,257 & & \\
\hline & Total & 1742,417 & 83 & & & \\
\hline
\end{tabular}

a. Dependent Variable: Kinerja

b. Predictors: (Constant), Knowledge Management, Talent Management 
Berdasarkan tabel 5 dapat diketahui bahwa nilai $F_{\text {hitung sebesar } 125,217 \text { pada }}$ taraf $\alpha=0,10$. Adapun $F_{\text {tabel }}$ diperoleh dengan rumus $\mathrm{df} 1=\mathrm{k}-1 ; \mathrm{df} 2=\mathrm{n}-\mathrm{k}(2 ; 81)$ adalah 2,37. Dengan demikin $F_{\text {hitung }}>F_{\text {tabel }}$ atau $125,217>2,37$ dengan level of significant $(\alpha) 0,000<0,10$ yang berarti bahwa variabel Talent Management dan Knowledge Management secara bersamasama (simultan) berpengaruh terhadap kinerja karyawan PT Perkebunan Nusantara
II Tanjung Morawa, artinya hipotesis diterima.

\section{Uji t (Parsial)}

Metode dalam penentuan $t_{\text {tabel }}$ menggunakan ketentuan tingkat signifikan $10 \%$, denga $\mathrm{df}=\mathrm{n}-\mathrm{k}-1$ (pada penelitian ini $\mathrm{df}$ $=84-3-1=80$ ), sehingga didapat nilai tabel sebesar 1,664. Hasil dari pengujian parsial adalah sebagai berikut:

Tabel 6

Hasil Uji t (Parsial)

Coefficients $^{\mathrm{a}}$

\begin{tabular}{|c|c|c|c|c|c|}
\hline \multirow[b]{2}{*}{ Model } & \multicolumn{2}{|c|}{$\begin{array}{l}\text { Unstandardized } \\
\text { Coefficients }\end{array}$} & \multirow{2}{*}{$\begin{array}{c}\begin{array}{c}\text { Standardized } \\
\text { Coefficients }\end{array} \\
\text { Beta }\end{array}$} & \multirow[b]{2}{*}{$\mathrm{T}$} & \multirow[b]{2}{*}{ Sig. } \\
\hline & $\mathrm{B}$ & Std. Error & & & \\
\hline $1 \quad$ (Constant) & 5,612 & 3,303 & & 1,699 & ,093 \\
\hline Talent Management & ,469 & 059 & ,575 & 7,952 & ,000 \\
\hline Knowledge Management & ,598 & ,115 & ,377 & 5,215 & ,000 \\
\hline
\end{tabular}

a. Dependent Variable: Kinerja

Dari tabel 6 di atas dapat dijelaskan bahwa:

1. Talent Management berpengaruh positif dan signifikan terhadap Kinerja karyawan dengan nilai thitung $=7,952>$ $t_{\text {tabel }}=1,664$ dan probabilitas 0,000 pada tingkat signifikan $10 \%$. Hal ini berarti semakin meningkat talent management dalam perusahaan, maka semakin meningkat kinerja karyawan.

2. Knowledge Management berpengaruh positif dan signifikan terhadap Kinerja karyawan dengan nilai $t_{\text {hitung }}=5,215>$ $\mathrm{t}_{\text {tabel }}=1,664$ dan probabilitas 0,000 pada tingkat signifikan $10 \%$. Hal ini berarti semakin meningkat knowledge management dalam perusahaan, maka semakin meningkat kinerja karyawan.

\section{Uji Koefisien Determinasi (Uji $\mathbf{R}^{2}$ )}

Determinan digunakan untuk mengetahui seberapa besar variabel independen mampu menjelaskan pengaruh variabel dependen.

Tabel 7

\section{R Square}

Model Summary

\begin{tabular}{|c|c|r|r|c|}
\hline Model & $\mathrm{R}$ & R Square & $\begin{array}{c}\text { Adjusted R } \\
\text { Square }\end{array}$ & $\begin{array}{c}\text { Std. Error of the } \\
\text { Estimate }\end{array}$ \\
\hline 1 &, $869 \mathrm{a}$ &, 756 &, 750 & 2,293 \\
\hline
\end{tabular}

a. Predictors: (Constant), Knowledge Management, Talent Management 
Dari tabel diatas, angka $\mathrm{R}$ sebesar 0,869 menunjukkan bahwa korelasi atau hubungan yang kuat antara variabel independen (talent management dan knowledge management) dengan variabel dependen (kinerja karyawan). Koefisien determinan (R square) sebesar 0,756. Nilai 0,756 ini menunjukkan bahwa variabel kinerja (Y) dapat dijelaskan oleh variabel talent management $\left(\mathrm{X}_{1}\right)$ dan knowledge management $\left(\mathrm{X}_{2}\right)$ secara bersama-sama sebesar $75,6 \%$ dan sisanya $24,4 \%$ dipengaruhi oleh variabel lain diluar model penelitian.

\section{Pembahasan Hasil Penelitian}

\section{Pengaruh Talent Management Terhadap Kinerja Karyawan PT. Perkebunan Nusantara II (Survei Pada Kantor Direksi Tanjung Morawa)}

Hasil penelitian yang dilakukan, bahwa talent management berpengaruh positif dan signifikan terhadap kinerja karyawan PT. Perkebunan Nusantara II Tanjung Morawa, sehingga dapat disimpulkan hipotesis pertama dapat diterima. Hal tersebut sesuai dengan pendapat dari Pella \& Inayati (dalam Syahputra, dkk. 2016) yang mengungkapkan bahwa salah satu manfaat dari pelaksanaan program talent management adalah tersedianya terus menerus karyawan yang mencapai potensi terbaik mereka masingmasing dan meningkatkan kinerja mereka. Hasil penelitian ini sejalan dengan penelitian sebelumnya yang dilakukan oleh Putiri Bhuana Katili, dkk. (2015) dimana variabel talent management (manajemen talenta) berpengaruh positif dan signifikan terhadap kinerja karyawan. Dalam penelitian lainnya juga menyebutkan bahwa variabel talent management mempunyai pengaruh positif terhadap kinerja karyawan.
Salah satu hal penting yang perlu diperhatikan oleh perusahaan adalah mengelola sumber daya manusia. Tanpa adanya SDM yang kuat dan handal perusahaan tidak dapat beroperasi optimal, karena sumber daya manusia yang menjadi penggerak utama roda bisnis perusahaan. Talent management sangatlah penting untuk perusahaan agar mampu mengelola sumber daya manusia bertalenta tinggi yang dapat membangun perusahaan untuk terus mencapai visi perusahaan.

Berdasarkan observasi awal pada PT. Perkebunan Nusantara II Tanjung Morawa, bahwa masih ada karyawan yang ditempatkan tidak sesuai dengan keahlian (talent) yang dimiliki karyawan sehingga hal tersebut akan mempengaruhi kinerja karyawan PT. Perkebunan Nusantara II Tanjung Morawa.

\section{Pengaruh Knowledge Management Terhadap Kinerja Karyawan PT. Perkebunan Nusantara II (Survei Pada Kantor Direksi Tanjung Morawa)}

Hasil penelitian yang dilakukan, bahwa knowledge management berpengaruh positif dan signifikan terhadap kinerja karyawan PT. Perebunan Nusantara II Tanjung Morawa, sehingga dapat disimpulkan hipotesis kedua diterima. Hasil penelitian ini sesuai dengan pendapat dari Ridha Choirun Nisa, dkk. (2016) menyatakan bahwa knowledge management (manajemen pengetahuan) adalah serangkaian proses penciptaan, pengkomunikasian dan penerapan knowledge perusahaan sebagai pembelajaran untuk meningkatkan kinerja karyawan maupun organisasi. Proses talent management karyawan tidak lepas kaitannya dengan pengelolaan pengetahuan yang tepat. 
Hasil penelitian ini sejalan dengan penelitian sebelumnya yang dilakukan oleh Boby Toefilus Warouw, dkk. (2014) dimana variabel knowledge management berpengaruh positif dan signifikan terhadap kinerja karyawan. Dalam penelitian lainnya juga menyebutkan bahwa variabel knowledge management mempunyai pengaruh positif terhadapad kinerja karyawan.

Knowledge management menjadi bidang yang penting dalam proses pembelajaran sebuah organisasi. Pengetahuan yang dimiliki oleh organisasi harus mampu memberikan kemajuan bagi organisasi itu sendiri. Untuk itu dibutuhkan manajemen yang kuat agar pengetahuan tersebut mengakar di setiap individu dalam organisasi dan tidak hilang begitu saja dengan didukung infrastruktur untuk penyebaran informasi di lingkungan organisasi.

Berdasarkan observasi awal pada PT. Perkebunan Nusantara II Tanjung Morawa, masih adanya karyawan yang kurangnya pengetahuan dalam pengoprasian komputer khususnya pada karyawan yang memiliki pendidikan tingkat SMU/Sederajat. Sehingga hal tersebut akan mempengaruhi kinerja karyawan PT. Perkebunan Nusantara II Tanjung Morawa.

\section{Pengaruh Talent Manajemen dan Knowledge Management Terhadap Kinerja Karyawan PT. Perkebunan Nusantara II (Survei Pada Kantor Direksi Tanjung Morawa)}

Dari hasil uji simultan (Uji F/ ANNOVA) maka dapat diperoleh bahwa variabel talent management dan knowledge managementberpengaruh positif terhadap kinerja karyawan PT. Perkebunan Nusantara II Tanjung Morawa, hal ini juga dapat disimpulkan bahwa talent management dan knowledge management berpengaruh secara bersama-sama terhadap kinerja karyawan PT. Perkebunan Nusantara II Tanjung Morawa.

Sehingga hasil penelitian ini menunjukkan bahwa seluruh hipotesis yang diajukan dalam penelitian ini dapat diterima, dan dinyatakan bahwa terdapat pengaruh yang positif dan signifikaan antara talent management dan knowledge managementterhadap kinerja karyawan PT. Perkebunan Nusantara II Tanjung Morawa. Hasil penelitian ini sejalan dengan pendapat Mahmudi (dalam Nisa, dkk., 2016) mengungkapkan bahwa terdapat beberapa faktor yang mempengaruhi kinerja SDM yaitu faktor individu, faktor kepemimpinan, faktor tim, faktor sistem, dan faktor situasi. Faktor pertama yang mempengaruhi kinerja karyawan adalah faktor individu yang didalamnya termasuk talenta (talent) dan pengetahuan (knowledge) yang dimiliki individu sejak lahir.

\section{KESIMPULAN}

Berdasarkan hasil penelitian dan pembahasan, maka dapat disimpulkan:

1. Variabel talent managementmemiliki nilai thitung $>$ tabel maka dapat disimpulkan bahwa dalam penelitian ini terdapat pengaruh positif dan signifikan terhadap kinerja karyawan PT. Perkebunan Nusantara II Tanjung Morawa, dengan $t_{\text {hitung }}$ 7,952 lebih besar dari $t_{\text {tabel }} 1,664$ dan nilai signifikannya lebih kecil dari 0,10 yaitu 0,000. Hal ini menyatakan bahwa hipotesis yang dirumuskan oleh peneliti yaitu terdapat pengaruh talent management terhadap kinerja karyawan di PT. Perkebunan Nusantara II (Survei Pada Kantor Direksi Tanjung Morawa), telah diuji dan terbukti dapat diterima kebenarannya.

2. Variabel knowledge management memiliki nilai $t_{\text {hitung }}>t_{\text {tabel }}$ maka dapat 
disimpulkan bahwa dalam penelitian ini terdapat pengaruh positif dan signifikan terhadap kinerja karyawan PT. Perkebunan Nusantara II Tanjung Morawa, dengan thitung 5,215 lebih besar dari tabel 1,664 dan nilai signifikannya lebih kecil dari 0,10 yaitu 0,000. Hal ini menyatakan bahwa hipotesis yang dirumuskan oleh peneliti yaitu terdapat pengaruh knowledge management terhadap kinerja karyawan di PT. Perkebunan Nusantara II (Survei Pada Kantor Direksi Tanjung Morawa), telah diuji dan terbukti dapat diterima kebenarannya.

3. Hasil penelitian yang ditemukan mendukung hipotesis ketiga bahwa variabel talent management dan knowledge management berpengaruh positif dan signifikan terhadap kinerja karyawan PT. Perkebunan Nusantara II Tanjung Morawa dengan nilai Fhitung sebesar 125,217 lebih besar dari Ftabel 2,37 dan nilai signifikansinya lebih kecil dari 0,10 yaitu 0,000 . Hal ini berarti hipotesis yang dirumuskan oleh peneliti yaitu terdapat pengaruh talent management dan knowledge management secara bersama-sama terhadap kinerja karyawan di PT. Perkebunan Nusantara II (Survei Pada Kantor Direksi Tanjung Morawa).

\section{SARAN}

Saran yang di sampaikan dari keseluruhan hasil penelitian ini adalah sebagai berikut:

1. Berdasarkan hasil penelitian tampak bahwa Talent Management dan Knowledge Management memiliki pengaruh terhadap Kinerja karyawan di Kantor Direksi PT. Perkebunan Nusantara II Tanjung Morawa. Terlebih untuk variabel talent management, maka perusahaan agar lebih meningkatkan dan memperhatikan sistem kompensasi dan retensi dalam perusahaan.

2. Demikian pula denga knowledge management sudah baik namun perlu ditingkatkan lagi, baik dalam teknologi, prosedur kerja, dan pengetahuan pribadi karyawan. Khususnya pada karyawan dengan pendidikan SMU/Sederajat.

3. Bagi peneliti selanjutnya, hasil penelitian ini dapat dilanjutkan dengan mengembangkan penelitian-penelitian lainnya, yaitu penelitian untuk mengungkap lebih jauh variabelvariabel yang mempengaruhi kinerja karyawan di PT. Perkebunan Nusantara II Tanjung Morawa atau di perusahaan lainnya.

\section{DAFTAR PUSTAKA}

Ahmed, Hossam Korany. 2016. "The Impact of Talent Management on The Competitive Advantage In The Organizations" Jurnal ISERD International Conference. ISBN: 97893-86083-33-3, Hal. 28-36. City University College of Ajman (CUCA).

Ahmed, Hossam Korany. 2016. "The Role of Knowledge Management In Developing The Talents Performance In Organizations" Jurnal International Journal of Management and Applied Science. ISSN: 23947926, Volume 2, Issue 12, Hal. 89-95. City University College of Ajman (CUCA).

Arikunto, Suharsini. 2006. Prosedure Penelitian. Edisi Revisi. Yogyakarta: PT. Rineka Cipta.

Budihardjo, Andreas. 2017. Knowledge Management Efektif Berinofasi 
Meraih Sukses. Jakarta: Prasetiya Mulya Publishing.

Ghozali, Imam. 2016. Aplikasi Analisis Multivariate dengan Program IBM SPSS 23. Semarang: Badan Penerbit Universitas Diponegoro.

Katili, Putri Buana, dkk. 2015. "Pengaruh Manajemen Talenta Dan Kompetensi Terhadap Kinerja Karyawan" Jurnal Seminar Nasional IENACO. ISSN 2337-4349, Hal. 618-625. Universitas Sultan Ageng Tirtayasa.

Kehinde, James Sunday. 2012. "Talent Management: Effect on Organizational Performance" Jurnal Macrothink Institute. ISSN 1941899X. Vol. 4, No. 2, Hal. 178-186. Faculty of Management Sciences Lagos State University.

Kosasih, Natalia dan Sri Budiani. 2007. "Pengaruh Knowledge Management Terhadap Kinerja Karyawan: Studi Kasus Departemen Front Office Surabaya Plaza Hotel" Jurnal Manajemen Perhotelan. Vol. 3, No. 2, Hal. 80-88. Fakultas Ekonomi Universitas Kristen Petra.

Kuncoro, Mudrajad. 2013. Metode Riset Untuk Bisnis dan Ekonomi Edisi Empat. Jakarta: Penerbit Erlangga.

Kusnaidi. 2002. Masalah, Kerjasama, Konflik dan Kinerja. Malang : Torada.

Laoh, Chres F.P, dkk. 2016. "Pengaruh Manajemen Pengetahuan, Keterampilan dan Sikap Kerja Terhadap Kinerja Pegawai (Studi Kasus Pada PT. National Nobu Bank Area Manado) Jurnal Berkala Ilmiah Efsiensi. Vol. 16, No. 04, Hal. 786793. Fakultas Ekonomi dan Bisnis, Universitas Sam Ratulangi, Manado.
M, Maya dan R. Thamilselvan. 2013. "Impact of Talent Management on Employee Performance And Organistional Effeciency In ITSP'S- With Reference To Chennai City" Jurnal IJER. pp. 453461.Vol. 10, No. 2, Hal. 453-461. Sathyabama Univerity, Chennai, India. 
Maeheriono. 2009. Pengatur Kinerja Berbasis Kompetensi. Bogor: Ghalia Indonesia.

Mangkunegara, A. A Anwar Prabu. 2009. Manajemen Sumber Daya Manusia. Bandung: PT. Remaja Rosdakarya.

Mangusho, Yona Sakaja, dkk. 2015. "Evaluation of Talent Management on Employees Performance in Beverage Industry: A Case of Delmonte Kenya Limited" International Journal of Humanities and Social Science. ISSN 2220-8488 (Print), 2221-0989 (Online). Vol. 5, No. 8, Hal. 191-199. Kenya.

Nisa, Ridha Choirun, dkk. 2016. "Pengaruh Manajemen Talenta dan Manajemen Pengetahuan Terhadap Kinerja Karyawan (Studi pada Karyawan PT. PLN (Persero) Distribusi Jawa Timur, Surabaya)" Jurnal Administrasi Bisnis (JAB). Vol. 39, No. 2, Hal. 141-148. Fakultas Ilmu Administrasi, Universitas Brawijaya.

Ridwan. 2007. Skala Pengukuran VariabelVariabel Penelitian. Bandung: Alfabeta.

Rivai, Veithzal. 2005. Kepemimpinan dan Perilaku Organisasi. Jakarta: PT. Raja Grafindo Persada.

Saefullah, Asep dan Ahmad Rusdiana. 2016. Manajemen Perubahan. Bandung: CV Pustaka Setia.

Siagian, Sondang P. 2007. Manajemen Sumber Daya Manusia. Cetakan Ke Empat Belas. Jakarta: Bumi Aksara.

Soejiono, Imam. 2005. Teknik Memimpin Pegawai dan Pekerja. Jakarta: Jayasakti.
Sugiyono. 2007. Metode Penelitian Administrasi. Bandung: Alfabeta.

Syahputra, Bobby Wahyu dan Syarifuddin. 2016. "Analisis Faktor Talent Management Pada Kinerja Dosen Fakultas Komunikasi dan Bisnis Universitas Telkom" Jurnal $e$ Proceeding of Management. ISSN 2355-9357. Vol. 3, No. 2, Hal. 1-9. Fakultas Komunikasi dan Bisnis, Universitas Telkom.

Utami, Sitti Rahmi, dkk. 2016. "Strategi Penerapan Knowledge Management Pada Karyawan PT Bank Muamalat Indonesia Tbk Cabang Makassar" Jurnal Analisis. ISSN 2303-100X. Vol. 5, No.1, Hal. 72-77. Fakultas Ekonomi, Universitas Hasanuddin.

Warouw, Boby Teofilus dan Lotje Kawet. 2014. "Knowledge Management Terhadap Kinerja Operasional Pada PT. BTN (Persero) Tbk. Cabang Manado" Jurnal EMBA. ISSN 23031174. Vol. 2, No. 1, Hal. 234-242. Fakultas Ekonomi dan Bisnis, Universitas Sam Ratulangi Manado.

Widodo, Suparno Eko. 2015. Manajemen Pengembangan Sumber Daya Manusia. Yogyakarta: Pustaka Pelajar. 